\title{
Inter-annual tropical Pacific climate variability in an isotope-enabled CGCM: implications for interpreting coral stable oxygen isotope records of ENSO
}

\author{
T. Russon ${ }^{1}$, A. W. Tudhope ${ }^{1}$, G. C. Hegerl ${ }^{1}$, M. Collins ${ }^{2}$, and J. Tindall ${ }^{3}$ \\ ${ }^{1}$ School of GeoSciences, University of Edinburgh, UK \\ ${ }^{2}$ College of Engineering, Mathematics and Physical Sciences, University of Exeter, EX4 4QF, UK \\ ${ }^{3}$ School of Earth and Environment, University of Leeds, UK \\ Correspondence to: T. Russon (tom.russon@ed.ac.uk)
}

Received: 18 January 2013 - Published in Clim. Past Discuss.: 7 February 2013

Revised: 19 June 2013 - Accepted: 20 June 2013 - Published: 22 July 2013

\begin{abstract}
Water isotope-enabled coupled atmosphere-ocean climate models allow for exploration of the relative contributions to coral stable oxygen isotope $\left(\delta^{18} \mathrm{O}_{\text {coral }}\right)$ variability arising from sea surface temperature (SST) and the isotopic composition of seawater $\left(\delta^{18} \mathrm{O}_{\mathrm{sw}}\right)$. The unforced behaviour of the isotope-enabled HadCM3 coupled general circulation model suggests that the extent to which inter-annual $\delta^{18} \mathrm{O}_{\mathrm{sw}}$ variability contributes to that in model $\delta^{18} \mathrm{O}_{\text {coral }}$ is strongly spatially dependent, ranging from being negligible in the eastern equatorial Pacific to accounting for $50 \%$ of $\delta^{18} \mathrm{O}_{\text {coral }}$ variance in parts of the western Pacific. In these latter cases, a significant component of the inter-annual $\delta^{18} \mathrm{O}_{\mathrm{sw}}$ variability is correlated to that in SST, meaning that local calibrations of the effective local $\delta^{18} \mathrm{O}_{\text {coral }}-\mathrm{SST}$ relationships are likely to be essential. Furthermore, the relationship between $\delta^{18} \mathrm{O}_{\mathrm{sw}}$ and SST can be non-linear, such that the model interpretation of central and western equatorial Pacific $\delta^{18} \mathrm{O}_{\text {coral }}$ in the context of a linear dependence on SST alone leads to overestimation (by up to $20 \%$ ) of the SST anomalies associated with large El Niño events. Intra-model evaluation of a salinity-based pseudo-coral approach shows that such an approach captures the first-order features of the model $\delta^{18} \mathrm{O}_{\mathrm{sw}}$ behaviour. However, the utility of the pseudo-corals is limited by the extent of spatial variability seen within the modelled slopes of the temporal salinity- $\delta^{18} \mathrm{O}_{\mathrm{sw}}$ relationship.
\end{abstract}

\section{Introduction}

The stable oxygen isotopic composition of reef-dwelling coral aragonite $\left(\delta^{18} \mathrm{O}_{\text {coral }}\right)$ represents a temperature dependent fractionation away from the ocean water from which calcification occurred. Consequently, $\delta^{18} \mathrm{O}_{\text {coral }}$ depends on both the temperature, referred to here as the sea surface temperature (SST), and the isotopic composition of the surface ocean water, denoted here as $\delta^{18} \mathrm{O}_{\mathrm{sw}}$. The temperature sensitivity of this fractionation yields a slope for the $\delta^{18} \mathrm{O}_{\text {coral }}-\mathrm{SST}$ relationship, denoted here as $R_{\mathrm{SST} \text {-coral }}$, of $\sim-0.2 \% \mathrm{~K}^{-1}$, e.g. Lough (2004), Juillet-Leclerc and Schmidt (2001), Corrège (2006), McConnaughey (1989b) and Zhou and Zheng (2003). This relationship provides the basis of the standard isotope palaeo-temperature equation, shown here in linear form as Eq. (1). The constant term, $C$, includes any vital-effect offsets from isotopic equilibrium (McConnaughey, 1989a, b).

$$
\delta^{18} \mathrm{O}_{\text {coral }}=\delta^{18} \mathrm{O}_{\mathrm{sw}}+R_{\mathrm{SST}-\mathrm{coral}}(\mathrm{SST}-C)
$$

Certain long-lived corals generate sufficiently high growth rates that they allow for the measurement of sub-annually resolved $\delta^{18} \mathrm{O}_{\text {coral }}$ records over periods of multiple decades. The combination of high growth rate, long lifespan and the simple, but well established, form of this proxy relationship provides a strong basis for the use of modern and fossil $\delta^{18} \mathrm{O}_{\text {coral }}$ variability as a tool to reconstruct annual to multidecadal tropical climate variability. Such records have been used to reconstruct pre-instrumental El Niño Southern Oscillation (ENSO) related inter-annual climate variability over 
the last millennium (Cobb et al., 2003; Dunbar et al., 1994), Holocene (Gagan et al., 2000; McGregor and Gagan, 2004), last glacial cycle (Tudhope et al., 2001) and as far back as the Pliocene (Watanabe et al., 2011). However, the interpretation of such records is inherently complicated by the fact that, in many tropical Pacific locations, the contribution from inter-annual $\delta^{18} \mathrm{O}_{\mathrm{sw}}$ variability, relative to that from SST, may not be negligible in the context of the resultant $\delta^{18} \mathrm{O}_{\text {coral }}$ variability (Tudhope et al., 2001; Cole and Fairbanks, 1990; Linsley et al., 2004). In regions with a very active hydrological cycle response to ENSO, such as the western Pacific warm pool (referred to hereafter as the warm pool) or the Inter-Tropical and South Pacific Convergence Zones (ITCZ/SPCZ), the $\delta^{18} \mathrm{O}_{\mathrm{sw}}$ contribution may indeed dominate the SST signal. Consequently, $\delta^{18} \mathrm{O}_{\text {coral }}$ records from these locations have also been used to infer past ENSO-related variability in the hydrological cycle (Cole and Fairbanks, 1990). Various aspects of the hydrological cycle act to influence $\delta^{18} \mathrm{O}_{\mathrm{sw}}$ variability, some of which may be relatively simple, such as the amount of local precipitation, and some of which may be very complex, such as the integrated hydrological cycle history of that precipitation.

Due to the dual climatic controls on $\delta^{18} \mathrm{O}_{\text {coral }}$, arising from SST and $\delta^{18} \mathrm{O}_{\mathrm{sw}}$, quantifying the spatial and temporal patterns of their relative influences remains a significant uncertainty in interpreting these important proxy records. This uncertainty provides the motivation for the present study. The particular focus here is on the inter-annual variability of such records, but almost all of what is discussed here would also apply to intra-annual variability as well. In order for $\delta^{18} \mathrm{O}_{\text {coral }}$ variability to be interpreted in terms of one of the two climatic proxy controls (SST and $\delta^{18} \mathrm{O}_{\mathrm{sw}}$, with the latter potentially leading by extension to some other hydrological cycle variable, such as precipitation or salinity) alone, one of several approaches may be followed, as listed below. These are presented in the case of interpreting the proxy records in terms of SST alone, but the $\delta^{18} \mathrm{O}_{\mathrm{sw}}$ case may be recovered by replacing " $\delta{ }^{18} \mathrm{O}_{\text {sw }}$ " with "SST" (and vice versa) where appropriate in the list.

1. If an independent constraint, relative to $\delta^{18} \mathrm{O}_{\text {coral }}$, is available on past variability in $\delta^{18} \mathrm{O}_{\mathrm{sw}}$ then Eq. (1) may be directly solved for the missing term. For example, in the case of reconstructing $\delta^{18} \mathrm{O}_{\mathrm{sw}}$, such an approach could potentially be pursued using an additional coupled proxy reconstruction of SST, such as $\mathrm{Sr} / \mathrm{Ca}$ trace metal records within the same coral skeletons (Gagan et al., 2000; Corrège, 2006; Linsley et al., 2000).

2. Constraints may exist on the extent and structure of modern time-domain $\delta^{18} \mathrm{O}_{\mathrm{sw}}$ variability and these could be assumed to be applicable on the historical timescales of interest.
3. Sufficient modern $\delta^{18} \mathrm{O}_{\text {coral }}$ and SST data may be available to empirically calibrate the $\delta^{18} \mathrm{O}_{\text {coral }}-\mathrm{SST}$ relationship at a given location and this relationship may be assumed to remain stationary on the timescales of interest.

4. An a priori assumption may be made regarding the time domain structure of the local $\delta^{18} \mathrm{O}_{\mathrm{sw}}$ variability. The simplest such assumption is that $\delta^{18} \mathrm{O}_{\mathrm{sw}}$ remains constant and hence contributes nothing to $\delta^{18} \mathrm{O}_{\text {coral }}$ variability. A slightly more sophisticated assumption might be that $\delta^{18} \mathrm{O}_{\mathrm{sw}}$ variability is independent of that in SST and hence contributes a degree of noise to the expected $\delta^{18} \mathrm{O}_{\text {coral }}-\mathrm{SST}$ relationship.

Approaches 1 and 2 are not considered further in the present study, as their utility is typically limited by proxy and/or instrumental data availability. In particular, instrumental records of $\delta^{18} \mathrm{O}_{\mathrm{sw}}$ are not available for most coral bearing locations and those that do exist are typically too sparse in the time domain to allow for robust quantification of inter-annual variability and its relationship with SST (Schmidt et al., 1999; LeGrande and Schmidt, 2006). Given that instrumental SST data is generally available, approach 3 is an option in all cases where a long modern coral is available. However, in situations where the unknown interannual $\delta^{18} \mathrm{O}_{\mathrm{sw}}$ variability is coupled to any extent to that in SST, as might be expected in the case of the closely coupled ocean-atmosphere dynamics of the ENSO system, the form of this calibration may not be a simple linear relation-

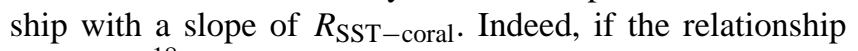
between $\delta^{18} \mathrm{O}_{\text {sw }}$ and SST is non-linear, then the form of the empirical $\delta^{18} \mathrm{O}_{\text {coral }}$-SST calibration will also be non-linear. In the absence of sufficient modern coral data to establish a calibration relationship, approach 4 provides the only universally available framework within which to interpret fossil $\delta^{18} \mathrm{O}_{\text {coral }}$ records.

The principle motivation for the present study is to explore the uncertainties associated with interpreting $\delta^{18} \mathrm{O}_{\text {coral }}$ records in the context of a priori assumptions regarding $\delta^{18} \mathrm{O}_{\mathrm{sw}}$ variability (i.e. approach 4 ) within a model-based realisation of the tropical climate system, for which both the SST and $\delta^{18} \mathrm{O}_{\text {sw }}$ fields are fully known. Such model-based climate realisations also allow for the evaluation to be made of the multi-decadal to centennial stationarity of the model relationships between $\delta^{18} \mathrm{O}_{\mathrm{sw}}$ and SST, which is not possible based on the instrumental record alone. This latter question is interesting in the context of ENSO variability, as temporal changes in the dominant spatial "modes" of ENSO variability (McPhaden et al., 2011; Yeh et al., 2009) might plausibly lead to changes in certain local/regional $\delta^{18} \mathrm{O}_{\mathrm{sw}}$ and SST relationships. This could mean that even in situations where modern $\delta^{18} \mathrm{O}_{\text {coral }}$-SST calibrations are available (allowing approach 3 to be followed) they may not be sufficiently long to fully capture the structures of these relationships. Coupled ocean-atmosphere general circulation models (CGCMs) that 
resolve both aspects of ENSO dynamics and also water isotope processes provide the only alternate climate realisation in which the current experiment may be undertaken. At present however, relatively few such models contain the required hydrological cycle processes to directly resolve water isotope variables. Consequently, this practical limitation has motivated an alternative, model "pseudo-coral" approach, based on the use of a proxy variable for $\delta^{18} \mathrm{O}_{\mathrm{sw}}$ that is available within standard non-isotope-enabled CGCM output, but that might be reasonably expected to respond to similar hydrological cycle processes (Thompson et al., 2011). A linear regression of such a field, for example sea surface salinity (SSS) (Cole and Fairbanks, 1990; Fairbanks et al., 1997), is then used to estimate variability in $\delta^{18} \mathrm{O}_{\mathrm{sw}}$ and hence $\delta^{18} \mathrm{O}_{\text {pseudo-coral. In the absence of temporal instrumental }}$ records of $\delta^{18} \mathrm{O}_{\mathrm{sw}}$ and SSS to constrain the $\delta^{18} \mathrm{O}_{\mathrm{sw}}$-SSS regression at each location of interest, the assumption has been made that the modern spatial slope between these paired observations of these variables (LeGrande and Schmidt, 2006) may usefully represent the temporal slopes. However, existing work with the isotope-enabled Goddard Institute for Space Studies ModelE-R CGCM suggests that substantial differences may exist between the temporal and spatial gradients of isotopic and conservative hydrological cycle tracers (LeGrande and Schmidt, 2009). Therefore, an additional question that may be addressed using fully isotope-enabled CGCMs is the evaluation of the uncertainties associated with the pseudo-coral approach, at least within the climate of that model.

The present study presents and analyzes results from a new multi-centennial pre-industrial control simulation of an isotope-enabled version of the UK Met Office coupled CGCM, HadCM3 (Gordon et al., 2000; Collins et al., 2001; Tindall et al., 2009). Following a brief description of the experimental design, the remainder of the study is then structured as follows. Firstly, the HadCM3 simulation is used to directly evaluate the spatial patterns across the tropical Pacific of inter-annual variability in SST and $\delta^{18} \mathrm{O}_{\mathrm{sw}}$. This in turn allows for the definition of a simple regime classification as to where the interpretation of model inter-annual $\delta^{18} \mathrm{O}_{\text {coral }}$ variability is likely to be robust to two simple assumptions regarding $\delta^{18} \mathrm{O}_{\mathrm{sw}}$, namely that it remains constant or that it varies independently of inter-annual SST fluctuations. Regardless of whether such assumptions are justified, the predicted form of the regional model relationships between the variability in $\delta^{18} \mathrm{O}_{\text {sw }}$ and SST may be evaluated in the model climate, which in turn allows for quantification of the extent of local and regional variability in the form of the $\delta^{18} \mathrm{O}_{\text {coral }}-\mathrm{SST}$ calibrations. The multi-decadal stationarity of these relationships is then evaluated within the context of the unforced model climate variability. An unforced control simulation is used, as recent work suggests that decadalcentennial changes in ENSO properties may be dominated by unforced processes (Wittenberg, 2009). Finally, an intramodel comparison of a SSS-derived pseudo-coral approach is made, in order to evaluate the extent to which the results derived from the present isotope-enabled CGCM could also have been obtained within a pseudo-coral framework.

\section{Experimental design and results}

The model results presented here are all derived from a $750 \mathrm{yr}$ pre-industrial control simulation of the isotopeenabled UK Met Office HadCM3 model (Gordon et al., 2000; Collins et al., 2001). All fields considered are presented on the model ocean grid $\left(1.25^{\circ}\right.$ latitude by $1.25^{\circ}$ longitude), aside from precipitation, which is presented on the model atmospheric grid $\left(2.5^{\circ}\right.$ latitude by $3.75^{\circ}$ longitude). Ocean fields are presented only for the tropical Pacific domain, taken here as that part of the Pacific Ocean basin which lies in the region $30^{\circ} \mathrm{S}$ to $30^{\circ} \mathrm{N}$ and $120^{\circ} \mathrm{E}$ to $70^{\circ} \mathrm{W}$. In the case of the ocean "surface variables", these represent an average of the upper $10 \mathrm{~m}$ of the water column. The inter-annual variability of the tropical climate in HadCM3 is known to be dominated by ENSO-like processes, albeit with significant spatial biases relative to observed ENSO behaviour (Collins et al., 2001; Guilyardi, 2006; Toniazzo, 2006). The inter-annual anomalies associated with all the monthly mean model fields considered here are calculated by removal of the average annual cycle, as calculated over the entire model simulation. When anomaly indices are presented for spatially averaged regions, the area-weighted mean of the field was initially calculated prior to the calculation of anomalies.

Water isotope processes are incorporated in HadCM3 as described in Tindall et al. (2009). The nature of the atmosphere and ocean GCMs employed in HadCM3 are such that $\mathrm{H}_{2} \mathrm{O}^{18}$ is incorporated within the atmosphere model as a set of parallel fields to the standard ones for $\mathrm{H}_{2} \mathrm{O}^{16}$. Within the ocean model, $\mathrm{H}_{2} \mathrm{O}^{18}$ is treated as a conservative tracer, representing a fraction of the total water present in that box. One consequence of this treatment is that $\delta^{18} \mathrm{O}_{\mathrm{sw}}$ within the ocean GCM in isolation should necessarily behave similarly to ocean salinity, which is also treated as a conservative tracer. Isotope fluxes are included in all situations where water fluxes exist in HadCM3, including a relatively simple treatment within the land surface scheme (MOSES2.1, Cox et al., 1999; Tindall et al., 2009). The isotope regime was spunup for $300 \mathrm{yr}$ from an assumed initialisation state of $0 \%$ in the oceans, atmosphere and sea ice and $-40 \%$ in snow and land ice. Even after this spin-up phase, the global surface ocean $\delta^{18} \mathrm{O}_{\mathrm{sw}}$ is seen to drift towards more positive values at a rate of $7.5 \times 10^{-5} \% \mathrm{yr}^{-1}$. This drift is likely to due to incomplete closure of the water isotope budget, resulting from parameterization within HadCM3 of an iceberg calving flux to balance the freshwater budget. The global drift across the $750 \mathrm{yr}$ simulations represents $\sim 200 \%$ of the magnitude of the inter-annual variability in the global average. Consequently, this trend is removed from the $\delta^{18} \mathrm{O}_{\mathrm{sw}}$ field prior to all subsequent analysis. The corresponding drifts in global 
SST and SSS are $-5.0 \times 10^{-5} \mathrm{Kyr}^{-1}$ and $4.6 \times 10^{-5} \mathrm{psu} \mathrm{yr}^{-1}$ respectively, both of which are over an order of magnitude smaller in relation to their respective inter-annual variability than that seen for $\delta^{18} \mathrm{O}_{\mathrm{sw}}$, such that no drift correction is applied to these fields. The $\delta^{18} \mathrm{O}_{\mathrm{sw}}$ field is treated as a conservative scalar field for the calculation of means and anomalies, as the amount of $\mathrm{O}^{16}$ in the ocean water may be considered invariant.

Figure 1 illustrates the mean climatology and inter-annual variance of the model fields for SST (Fig. 1a, b), SSS (Fig. 1c, d), precipitation (Fig. 1e, f) and detrended $\delta^{18} \mathrm{O}_{\mathrm{sw}}$ (Fig. 1g, h). The spatial biases associated with the HadCM3 ENSO phenomenon are most easily seen on the SST panels, for which the climatological cold tongue extends too far westward, an example of the so-called CGCM cold tongue bias (Guilyardi, 2006). The extent of this bias in HadCM3 is such that the equatorial region for which inter-annual SST anomalies are positively correlated to those in the eastern equatorial Pacific extends right across the tropical Pacific domain (to $120^{\circ} \mathrm{E}$ ), rather than to $\sim 160^{\circ} \mathrm{E}$ as in the instrumental HadISST data (Rayner et al., 2003). In consequence of this, inter-annual SST variability in the western equatorial Pacific is greater in amplitude than that seen in the instrumental climate. For example, the inter-annual variance of the SST field averaged over the western equatorial Pacific NINO4 box $\left(5^{\circ} \mathrm{N}\right.$ to $5^{\circ} \mathrm{S}$ and $160^{\circ} \mathrm{E}$ to $210^{\circ} \mathrm{E}$ ) exceeds that seen in HadISST by around a third. The relative magnitude of this bias attains a maximum value in the westernmost part of the model cold tongue, where the model inter-annual SST variance is over four times that seen in HadISST. In the case of the model precipitation flux field, the very large spatial changes in average precipitation values (Fig. 1e) mean that it is more useful to consider the relative extent of interannual precipitation variability, given here by the dimensionless ratio of the inter-annual variance to the squared mean of the precipitation field (Fig. 1f). The climatological mean of the $\delta^{18} \mathrm{O}_{\text {sw }}$ field, as seen in Fig. $1 \mathrm{~g}$, is seen to capture the first-order structure and absolute values seen in gridded interpolations of the available instrumental data (LeGrande and Schmidt, 2006; Tindall et al., 2009). Further validation of the HadCM3 isotope regime using the isotopic composition of precipitation is available in Tindall et al. (2009).

The model $\delta^{18} \mathrm{O}_{\text {coral }}$ field (Fig. 1i, j) is calculated directly using the SST and $\delta^{18} \mathrm{O}_{\mathrm{sw}}$ fields using Eq. (1), with an assumed $R_{\mathrm{SST} \text {-coral }}$ value of $-0.23 \% \circ \mathrm{K}^{-1}$, according to Zhou and Zheng (2003), and a $C$ value of $3.8 \%$, according to Epstein et al. (1953). Although corals are known to show significant offsets from isotopic equilibrium (McConnaughey, 1989a, b), which implies considerable uncertainty in the value of $C$, the focus on variability (rather than absolute values) within this study means that this uncertainty is largely irrelevant to the subsequent discussion. However, uncertainty in the value of $R_{\mathrm{SST} \text {-coral }}$ carries through into all the subsequent analyses. The Zhou and Zheng (2003) value is for inorganic aragonite precipitation experiments, although this remains within one decimal point of the Epstein et al. (1953) value for calibration experiments with organic calcite. Compiled calibration studies on coral aragonite suggest values within \pm 0.05 of the inorganic aragonite value (Corrège, 2006; Lough, 2004), although sitespecific studies suggest that variability may exist in the range -0.10 to $-0.34 \% \mathrm{~K}^{-1}$ (Evans et al., 2000). Whilst model $\delta^{18} \mathrm{O}_{\text {coral }}$ results are presented in the first instance for the $-0.23 \% \mathrm{~K}^{-1}$ case, sensitivity tests to values in the range $-0.20 \% \mathrm{~K}^{-1}$ to $-0.25 \% \mathrm{~K}^{-1}$ were also performed to account for a $\pm 10 \%$ uncertainty in the assumed global value of the $R_{\mathrm{SST} \text {-coral }}$ slope. No additional noise is added into the model $\delta^{18} \mathrm{O}_{\text {coral values, such that this field represents }}$ the idealised response of the coral stable oxygen isotope proxy system to the model climate. The mean $\delta^{18} \mathrm{O}_{\text {coral }}$ field (Fig. 1i) follows the first order features of the associated (inverted) SST field, whereas the inter-annual $\delta^{18} \mathrm{O}_{\text {coral }}$ variance (Fig. 1j) represents a combination of the associated SST (Fig. 1b) and $\delta^{18} \mathrm{O}_{\mathrm{sw}}$ (Fig. 1h) fields. This latter observation qualitatively supports the potential importance of both these climatic controls on the inter-annual variability seen in tropical Pacific $\delta^{18} \mathrm{O}_{\text {coral }}$ records.

The experimental design involves two main structural assumptions, within the context of which all subsequent results and discussions must be viewed. Firstly, if the $R_{\mathrm{SST}-\text { coral }}$ parameter in Eq. (1) contains spatial variability, perhaps due to regional biotic effects (Evans et al., 2000), that is beyond the $\pm 10 \%$ uncertainty considered here, then this could substantially impact the local scale interpretation of the model results. Secondly, there is the inherent assumption that the HadCM3 tropical climate and its inter-annual variability are usefully representative of the real climate system. Given that significant biases exist within the HadCM3 ENSO phenomenon, both in terms of its spatial manifestation and average amplitude (Guilyardi, 2006), it follows that the model results should not be directly translated to interpretation of the real system. Nonetheless, the first-order features of the model behaviour may still provide useful insights into the corresponding first-order patterns within the real system.

\section{Discussion}

\subsection{The spatial structure of the $\delta^{18} \mathrm{O}_{\mathrm{sw}}$ and SST contributions to $\delta^{18} \mathrm{O}_{\text {coral variance }}$}

When considering the variance of inter-annual anomaly timeseries as a measure of the inter-annual variability of $\delta^{18} \mathrm{O}_{\text {coral }}$ records, as denoted by $\operatorname{var}\left(\delta^{18} \mathrm{O}_{\text {coral }}\right)$, it follows from Eq. (1) that the contribution from variability in $\delta^{18} \mathrm{O}_{\mathrm{sw}}$ to this term depends not only on $\operatorname{var}\left(\delta^{18} \mathrm{O}_{\mathrm{sw}}\right)$ itself, but also on the covariance of $\delta^{18} \mathrm{O}_{\mathrm{sw}}$ with SST, denoted $\operatorname{cov}\left(\mathrm{SST}, \delta^{18} \mathrm{O}_{\mathrm{sw}}\right)$. The combined contribution from these two terms to the total $\operatorname{var}\left(\delta^{18} \mathrm{O}_{\text {coral }}\right)$, expressed as a fraction of that total, is defined as the " $F_{\mathrm{sw}}$ " metric (Eq. 2). 

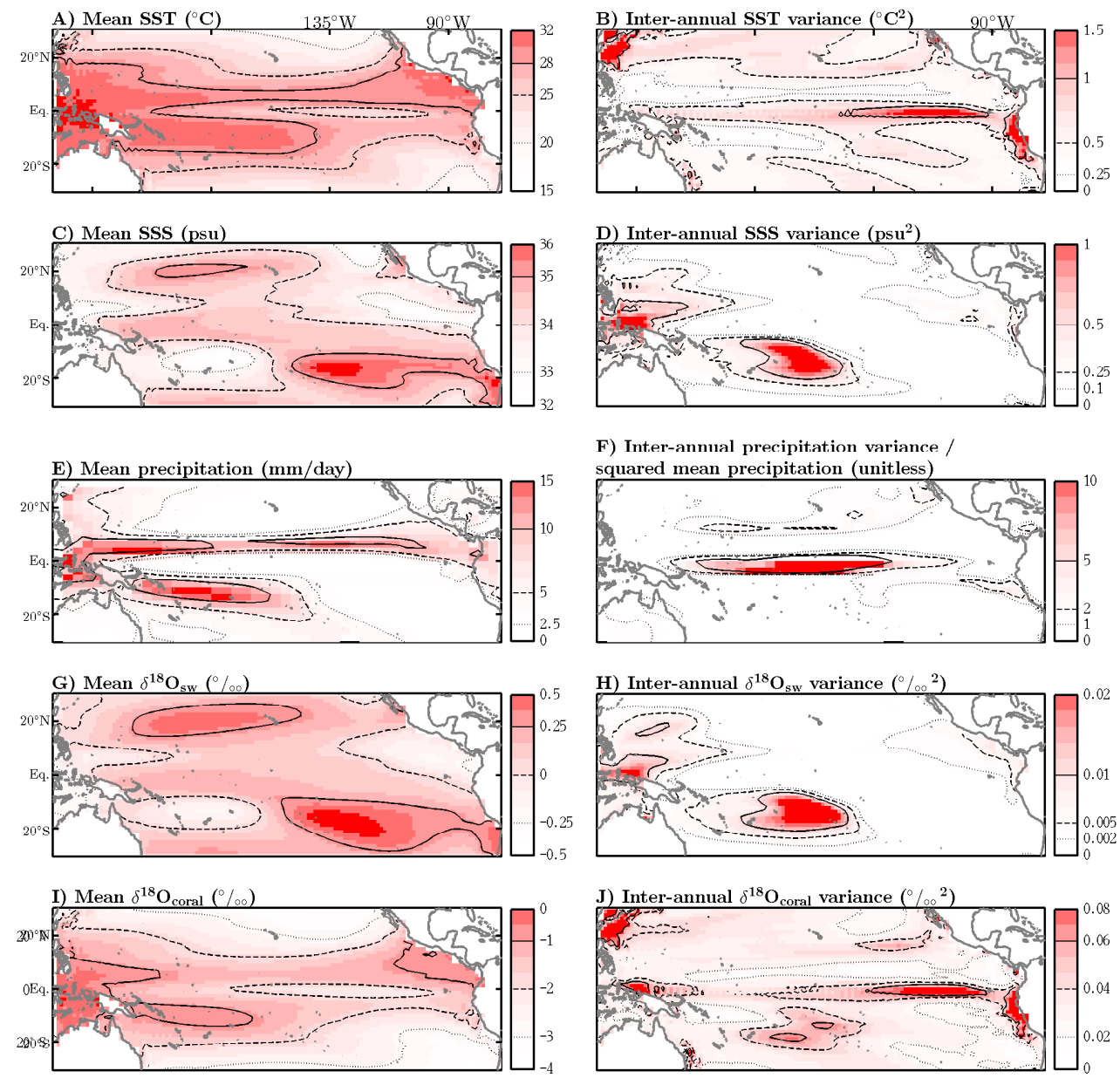

Fig. 1. The mean climatology (left hand panels) and inter-annual variance (right hand panels) of selected model fields over the entire $750 \mathrm{yr}$ control simulation, displayed for the tropical Pacific domain. The entire simulation was used as the reference period for the removal of the annual climatology prior to the variance calculations. Note that the precipitation variability $(\mathbf{F})$ is presented as a dimensionless ratio of the inter-annual variance of precipitation divided by the squared mean values. The contoured levels are highlighted on the colour bars.

$F_{\mathrm{sw}}=\frac{\operatorname{var}\left(\delta^{18} \mathrm{O}_{\mathrm{sw}}\right)+2 R_{\mathrm{SST}-\mathrm{coral}} \operatorname{cov}\left(\mathrm{SST}, \delta^{18} \mathrm{O}_{\mathrm{sw}}\right)}{\operatorname{var}\left(\delta^{18} \mathrm{O}_{\mathrm{coral}}\right)}$

The magnitude of $F_{\mathrm{sw}}$ represents the fraction of model $\operatorname{var}\left(\delta^{18} \mathrm{O}_{\text {coral }}\right)$ that would have been "missed" if $\delta^{18} \mathrm{O}_{\text {sw }}$ in Eq. (1) had been assumed constant. Hence, this metric allows for ready evaluation of the validity of that assumption within the model climate. Within regions of the tropical Pacific for which $\left|F_{\mathrm{sw}}\right|<0.1$ (those lying between the solid red and blue contours on Fig. 2a), the interpretation of $\operatorname{var}\left(\delta^{18} \mathrm{O}_{\text {coral }}\right)$ in terms of inter-annual SST variability alone would lead to an error of less than $10 \%$ of the true value. This $10 \%$ level is taken as being one that could be reasonably considered to be negligible for the remainder of the study. The spatial distribution of $\left|F_{\mathrm{sw}}\right|$ is seen to follow the first-order pattern of mean precipitation within the model (Fig. 1e), consistent with precipitation-related factors dominating $\delta^{18} \mathrm{O}_{\mathrm{sw}}$ variability (Tindall et al., 2009). $\left|F_{\mathrm{sw}}\right|$ values of less than 0.1 occur across much of the subtropical Eastern and centraleastern equatorial Pacific, including most of the NINO3 box region $\left(5^{\circ} \mathrm{N}\right.$ to $5^{\circ} \mathrm{S}$ and $210^{\circ} \mathrm{E}$ to $270^{\circ} \mathrm{E}$; Fig. 2a). Model coral records from these locations could, therefore, on these criteria justifiably be interpreted directly in terms of interannual SST variability alone. However, the value of $F_{\text {sw }}$ generally becomes larger as one moves westward in the tropical Pacific and such an interpretation would not be justified in most locations west of the dateline, or in the northeastern sub-equatorial Pacific (Fig. 2a). The two regions for which the highest $\left|F_{\mathrm{sw}}\right|$ values are obtained (exceeding 0.5 , such that more than half of model coral $\operatorname{var}\left(\delta^{18} \mathrm{O}_{\text {coral }}\right)$ would have been missed in an SST-only interpretation) are the western Pacific warm pool and the SPCZ (Fig. 2a). However, $\left|F_{\mathrm{sw}}\right|$ does not exceed 0.9 in either region, such that there are no locations where the model SST contribution could be neglected at the same relative confidence level as that for which $\delta^{18} \mathrm{O}_{\mathrm{sw}}$ 
A) $\mathbf{F}_{\mathrm{sw}}$, fraction of $\delta^{18} \mathrm{O}_{\text {coral variance from } \delta^{18} \mathrm{O}_{\mathrm{sw}}}$

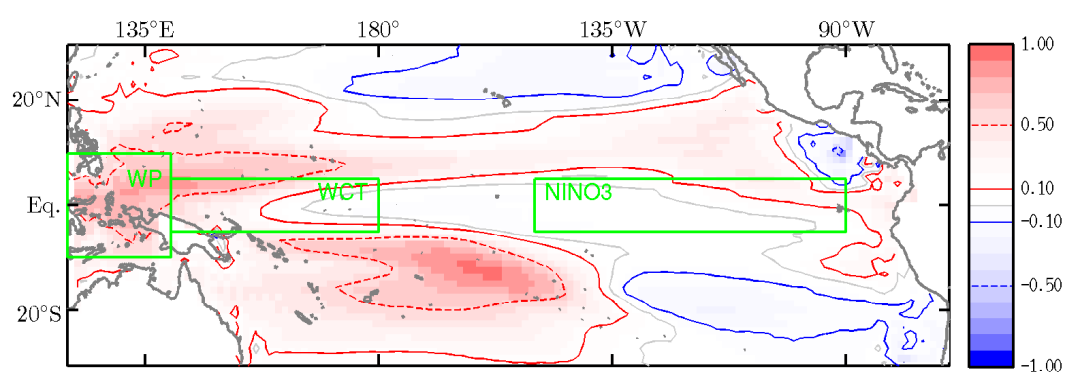

B) $\mathbf{F}_{\text {cov }}$, fraction of $\delta^{18} \mathrm{O}_{\text {coral variance from covariance of SST and } \delta^{18} \mathrm{O}_{\mathrm{sw}}}$

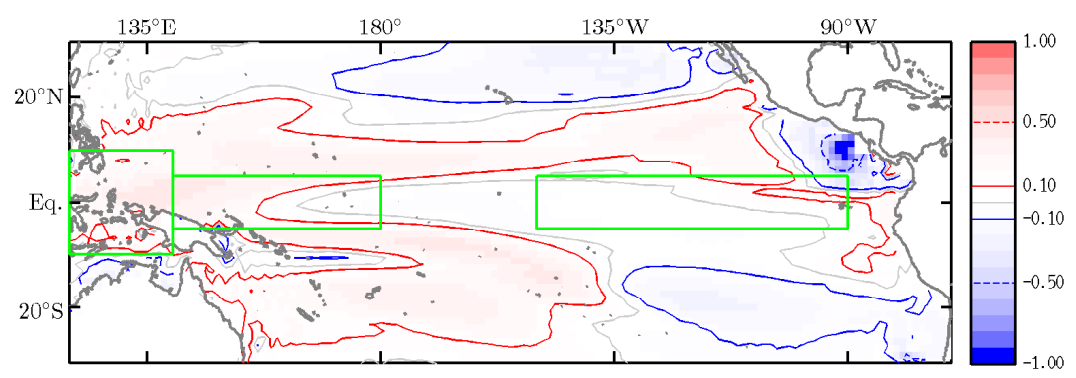

C) Interpretation of $\mathbf{F}_{\mathrm{sw}}$ and $\mathbf{F}_{\mathrm{cov}}$ metrics

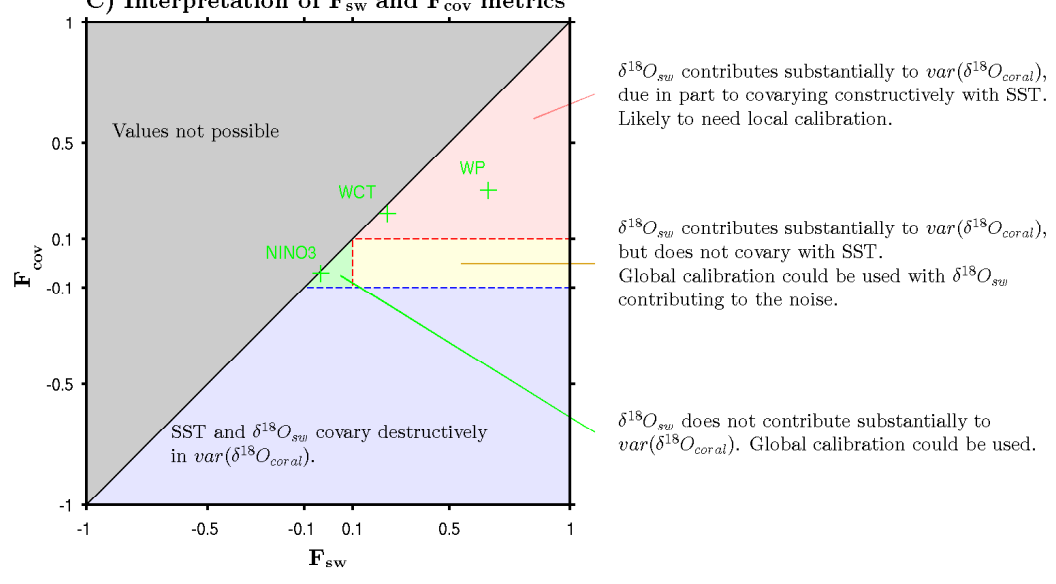

Fig. 2. The spatial distributions over the tropical Pacific domain of (A) the $F_{\mathrm{sw}}$ metric, which shows the fraction of model inter-annual

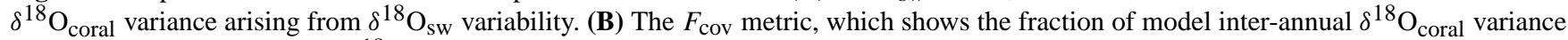
arising from the component of $\delta^{18} \mathrm{O}_{\mathrm{sw}}$ variability that co-varies with that in SST. The three regional boxes discussed in the text are highlighted in green, $\mathrm{WP}=$ warm pool, WCT $=$ western cold tongue. Panel $(\mathbf{C})$ gives a schematic guide to the interpretation of the $F_{\mathrm{sw}}$ and $F_{\mathrm{cov}}$ metrics . Regions of $F_{\mathrm{sw}}$ and $F_{\mathrm{cov}}$ space that are relevant to the discussion in the text are identified by color shading and briefly described in annotation labels. The green markers show where the metric values associated with the averages over the three boxes highlighted on panels $(\mathbf{A})$ and $(\mathbf{B})$ plot within such a framework.

can be so neglected in the eastern equatorial Pacific. Consequently, interpreting western Pacific model coral records in terms of hydrological cycle variability alone is likely to be relatively more challenging than interpreting eastern Pacific model corals in terms of SST variability alone. A caveat to this result is that the extent of the model cold tongue bias means that inter-annual SST variability in the western equatorial Pacific and warm pool region is generally larger in amplitude than is seen in the real climate system. However, in the case of the warm pool (where HadCM3 inter-annual SST variance only exceeds that seen in HadISST by $\sim 10 \%$ ) the model result of mixed SST and hydrological cycle influences on $\delta^{18} \mathrm{O}_{\text {coral }}$ is unlikely to be contingent on the model biases.

The sign of $F_{\mathrm{sw}}$ relates to the extent of any correlation present between inter-annual $\delta^{18} \mathrm{O}_{\mathrm{sw}}$ and SST variability. A negative value of $F_{\mathrm{sw}}$ can only arise when the $\operatorname{cov}\left(\mathrm{SST}, \delta^{18} \mathrm{O}_{\mathrm{sw}}\right)$ term is negative, indicating that interannual $\delta^{18} \mathrm{O}_{\mathrm{sw}}$ variability is positively correlated with that 
in $\mathrm{SST}$, leading to a reduction in $\operatorname{var}\left(\delta^{18} \mathrm{O}_{\text {coral }}\right)$ compared to what would have been seen were the two climatic variables to be independent. The only tropical Pacific regions for which $F_{\text {sw }}<-0.1$ are parts of the subtropical eastern $\mathrm{Pa}-$ cific and the central American coastal domain (Fig. 2a). Conversely, positive $F_{\mathrm{sw}}$ values arise if inter-annual $\delta^{18} \mathrm{O}_{\mathrm{sw}}$ variability is anti-correlated with SST, as might be expected from a SST-driven precipitation anomaly effect (Tindall et al., 2009). However, positive $F_{\text {sw }}$ values may also arise in cases where inter-annual $\delta^{18} \mathrm{O}_{\mathrm{sw}}$ variability is non-negligible, but largely (or entirely) independent of the corresponding SST variability. This situation would imply that the assumption of a white noise contribution from the $\delta^{18} \mathrm{O}_{\mathrm{sw}}$ variability to a SST-dominated model coral could be justified, even though the more aggressive one of constant $\delta^{18} \mathrm{O}_{\text {sw }}$ would not be. Consequently, to determine which of these scenarios applies across the large areas of the western Pacific for which $F_{\text {sw }}>0.1$, the contribution from the $\delta^{18} \mathrm{O}_{\text {sw }}-\mathrm{SST}$ covariance term alone is also considered independently as a second metric, " $F_{\text {cov }}$ ", again expressed as the fraction of the total $\operatorname{var}\left(\delta^{18} \mathrm{O}_{\text {coral }}\right)$ for which it accounts (Eq. 3). The interpretation of the $F_{\mathrm{sw}}$ and $F_{\mathrm{cov}}$ metrics is summarised on Fig. 2c.

$F_{\text {cov }}=\frac{2 R_{\mathrm{SST}-\mathrm{coral}} \operatorname{cov}\left(\mathrm{SST}, \delta^{18} \mathrm{O}_{\mathrm{sw}}\right)}{\operatorname{var}\left(\delta^{18} \mathrm{O}_{\mathrm{coral}}\right)}$

There are very few regions for which the overall $\delta^{18} \mathrm{O}_{\mathrm{sw}}$ contribution is non-negligible $\left(\left|F_{\mathrm{sw}}\right|>0.1\right)$, but the covariance term is not also substantially positive $\left(F_{\text {cov }}>0.1\right)$ (Fig. 2a, b). This means that almost everywhere $\delta^{18} \mathrm{O}_{\mathrm{sw}}$ contributes substantially to inter-annual model coral variability, it does so with a significant degree of anti-correlation to the associated inter-annual fluctuations in SST. Such a scenario is to be expected in a closely coupled SST-hydrological cycle system such as ENSO, but means that the treatment of $\delta^{18} \mathrm{O}_{\mathrm{sw}}$ as a white noise addition to a simple $\delta^{18} \mathrm{O}_{\text {coral }}$ to SST calibration is unlikely to be an acceptable substitute for knowledge of the true local calibration at locations for which $\left|F_{\mathrm{sw}}\right|>0.1$. Within the warm pool and SPCZ regions, where the overall $\delta^{18} \mathrm{O}_{\mathrm{sw}}$ contribution is the most important, $F_{\text {cov }}$ rarely exceeds 0.2 and hence accounts for only a quarter to a half of the value of $F_{\mathrm{sw}}$. In these cases, a substantial component of $\operatorname{var}\left(\delta^{18} \mathrm{O}_{\text {coral }}\right)$ arises both from inter-annual $\delta^{18} \mathrm{O}_{\mathrm{sw}}$ variability that is correlated to that in SST and that which is independent of it. Even if model $\delta^{18} \mathrm{O}_{\text {coral }}$ records from these locations were to be interpreted as an ENSO climate proxy, representing the co-varying components of $\delta^{18} \mathrm{O}_{\mathrm{sw}}$ and SST variability, rather than either of those variables alone, such a calibration would still only be able to explain at most $\sim 75 \%$ of the total $\operatorname{var}\left(\delta^{18} \mathrm{O}_{\text {coral }}\right)$. A caveat to this result is that the extent of the model cold tongue bias means that inter-annual SST variability in most of the warm pool box remains positively correlated to that in the NINO3 region (termed the positive ENSO phase region). However, similar values of
$F_{\text {cov }}$ to those seen in the warm pool box are seen in the subequatorial negative ENSO phase regions within the model (Fig. 2b), suggesting that the effect of averaging over the different phase regions may be relatively small.

The model values of both $F_{\mathrm{sw}}$ and $F_{\mathrm{cov}}$ are necessarily dependent on the assumed value of $R_{\mathrm{SST} \text {-coral }}$. However, the uncertainty in $F_{\mathrm{sw}}\left(F_{\mathrm{cov}}\right)$ arising from the sensitivity tests

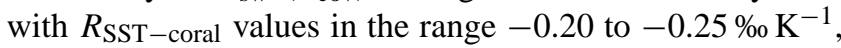
is seen to be less than $\pm 0.1( \pm 0.05)$ in the case of more than $95 \%$ of the tropical Pacific grid boxes. Consequently, whilst the exact metric values presented here are contingent on the imposed parameters of the assumed proxy relationship, the general conclusions of the study are unlikely to be altered by local/regional fluctuations within the range investigated here.

\subsection{Regional relationships between inter-annual variability in $\delta^{18} O_{\text {coral }}, \delta^{18} O_{\text {sw }}$ and SST}

The isotope-enabled HadCM3 output defines the temporal relationships expected at different locations between $\delta^{18} \mathrm{O}_{\mathrm{sw}}$ and SST. If the form of Eq. (1) is assumed to be valid, then the expected model calibration relationship between (idealised) inter-annual $\delta^{18} \mathrm{O}_{\text {coral }}$ and SST variability at any given location is also constrained. To illustrate the range of variability seen in these relationships on the regional scale, scatter plots of the spatially averaged indices of the monthly inter-annual anomaly values are presented in Fig. 3 for the NINO3 box, a western cold tongue region (WCT, defined here as $5^{\circ} \mathrm{N}$ to $5^{\circ} \mathrm{S}$ and $140^{\circ} \mathrm{E}$ to $180^{\circ} \mathrm{E}$ ) and a model warm pool region (defined here as $10^{\circ} \mathrm{N}$ to $10^{\circ} \mathrm{S}$ and $120^{\circ} \mathrm{E}$ to $140^{\circ} \mathrm{E}$ ). The locations of these three regions are shown by the green boxes on Fig. 2 and are chosen principally to represent an east-west traverse across the positive model ENSO phase region in the equatorial Pacific, across which the relative importance of the $\delta^{18} \mathrm{O}_{\mathrm{sw}}$ contribution to model $\operatorname{var}\left(\delta^{18} \mathrm{O}_{\text {coral }}\right)$ increases as one moves westward. The WCT region is so named as it represents the western part of the model SST cold tongue and is hence located further westwards than the equivalent climatological domain in the real system. The monthly anomaly data points on Fig. 3 are colorcoded according to the value of the associated NINO3 SST anomalies, with the upper (lower) ten percentiles coloured red (blue) to represent eastern Pacific El Niño (La Niña) type climatic conditions. In the case of the warm pool box, the model cold tongue bias results in most of this domain lying weakly within the positive ENSO phase region, rather than within the negative ENSO phase region as in the real climate system.

For the NINO3 box, $\delta^{18} \mathrm{O}_{\text {sw }}$ and SST are largely independent of one another (Fig. 3c) and the magnitude of the latter is relatively large in terms of $\operatorname{var}\left(\delta^{18} \mathrm{O}_{\text {coral }}\right)$, implying a low $F_{\text {sw }}$ value and a near-linear relationship between SST and $\delta^{18} \mathrm{O}_{\text {coral }}$ (Fig. 3f). The slope of the best-fit linear regression through this data is indistinguishable (to 2 d.p.) from that of the imposed proxy relationship slope (shown as the green 

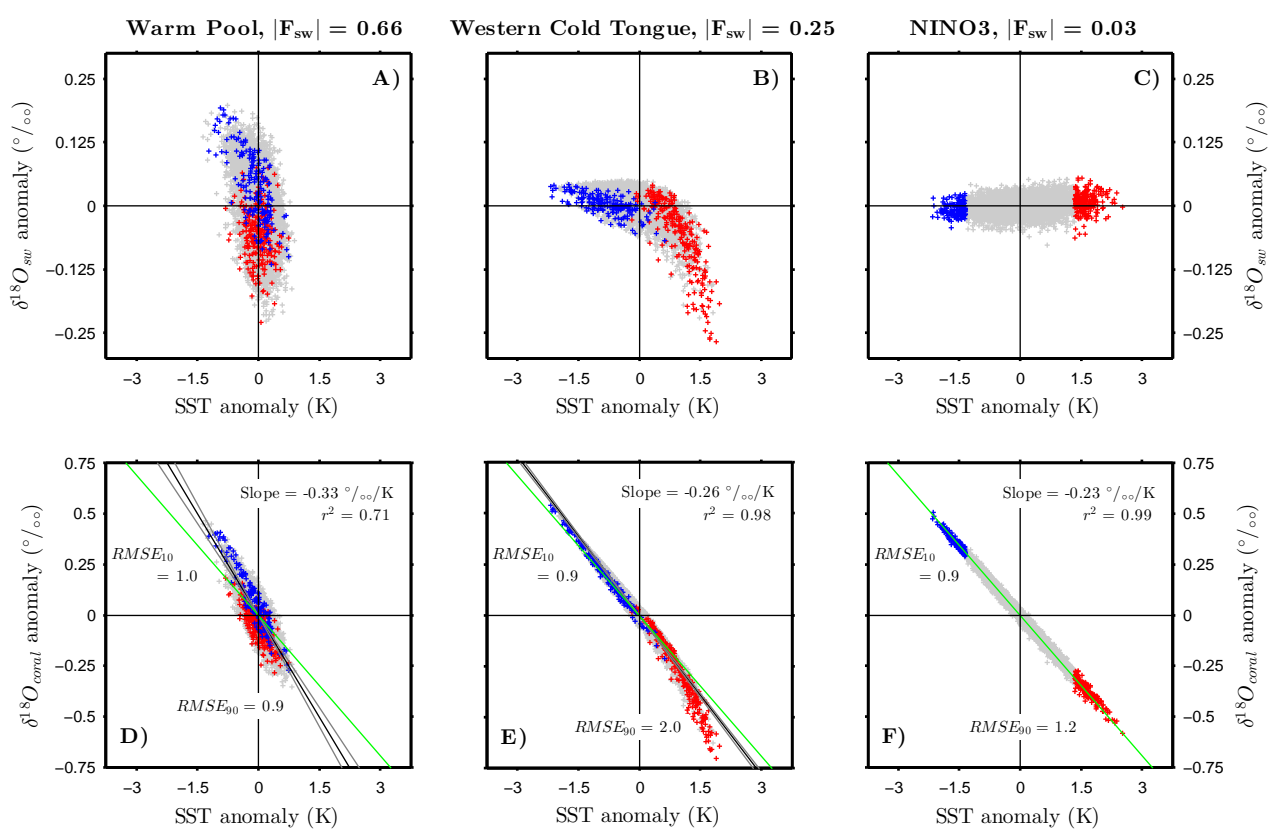

Fig. 3. Scatter plots of the relationships between the inter-annual monthly anomalies of $\delta^{18} \mathrm{O}_{\mathrm{sw}}$ and SST (upper panels) and $\delta^{18} \mathrm{O}_{\text {coral }}$ and SST (lower panels), as calculated for the spatial averaged indices over the warm pool, western cold tongue and NINO3 boxes. The locations of these regions are shown on Fig. 2. The data points are color-coded according to the corresponding NINO3 SST anomalies, with the upper ten percentiles shown in red (eastern Pacific El Niño type conditions) and the lower ten percentiles in blue (eastern Pacific La Niña type conditions). The black regression lines on the lower plots show the best-fit linear regressions through the data, with the slope and $r^{2}$ values annotated on the plots. The RMSE 10 and RMSE 90 metric values associated with the best-fit linear slopes are also annotated on these plots. The grey lines show the two-tailed $95 \%$ confidence bounds on the best-fit regression slopes, based on the assumption of an assumed decorrelation time of $4 \mathrm{yr}$. The green lines show the imposed $R_{\mathrm{SST}-\text { coral }}$ slope of $-0.23 \%$ 和 ${ }^{-1}$.

references line of $-0.23 \% \mathrm{~K}^{-1}$ on Fig. $3 \mathrm{~d}-\mathrm{f}$ ). As discussed above, an averaged NINO3 box $\delta^{18} \mathrm{O}_{\text {coral }}$ record could, therefore, be interpreted in terms of inter-annual SST variability alone with only relatively small resultant uncertainties. In contrast, the inter-annual variability in $\delta^{18} \mathrm{O}_{\mathrm{sw}}$ and SST seen within both the WCT and warm pool boxes clearly contains structured relationships (Fig. 3a, b). The overall sense of this dependency is seen in both cases to be an anti-correlation, indicative of the positive $F_{\text {cov }}$ metric values associated with the western Pacific (Fig. 2b) and consistent with SST-driven inter-annual precipitation anomalies. However, the western Pacific $\delta^{18} \mathrm{O}_{\mathrm{sw}}$-SST relationships are also seen to be nonlinear and this is particularly pronounced in the case of the WCT box. The extent of the WCT box non-linearity is sufficiently important as to substantially impact the associated $\delta^{18} \mathrm{O}_{\text {coral }}$-SST relationship, such that although the best-fit linear slope (black regression line, with the two-tailed $95 \%$ confidence interval on the slope shown by the grey lines and calculated using the conservative assumption of a decorrelation time of $4 \mathrm{yr}$ ) remains close to that of the imposed proxy relationship, the El Niño tail deviates substantially from such a trend (Fig. 3e). A non-linear relationship of this kind could have important implications for interpreting proxy records and is investigated further in the following paragraphs. The warm pool box $\delta^{18} \mathrm{O}_{\mathrm{sw}}-\mathrm{SST}$ relationship is both steeper and more linear than that for the WCT box, leading to a situation in which the associated $\delta^{18} \mathrm{O}_{\text {coral }}-\mathrm{SST}$ relationship does not visually manifest substantial non-linearity, but is described by a best-fit linear slope that deviates by $\sim 40 \%$ from the imposed value (Fig. 3d). A similar relative deviation away from unity is also necessarily seen in the slope of the warm pool $\delta^{18} \mathrm{O}_{\text {coral }}-\delta^{18} \mathrm{O}_{\text {sw }}$ relationship (not shown). There is also considerably more spread around the best-fit linear $\delta^{18} \mathrm{O}_{\text {coral }}-\mathrm{SST}$ model than was seen for either the NINO3 or WCT boxes. Model $\delta^{18} \mathrm{O}_{\text {coral }}$ records from the warm pool region may still be interpretable in terms of a linear relationship with SST (or $\delta^{18} \mathrm{O}_{\mathrm{sw}}$ ) variability alone, but such an approach requires the establishment of a regional calibration of the desired relationship and even then this should be expected to contain considerable noise.

To quantify the extent of non-linearity in the predicted model $\delta^{18} \mathrm{O}_{\text {coral }}$-SST calibration relationships, the root mean square error (RMSE) associated with the best-fit linear $\delta^{18} \mathrm{O}_{\text {coral }}$-SST relationships are calculated over the upper and lower ten percentiles of the SST data and then divided by the value for the entirety of the data set. These upper-tail and lower-tail non-linearity $\delta^{18} \mathrm{O}_{\text {coral }}$-SST metrics are referred to as $\mathrm{RMSE}_{90}$ and $\mathrm{RMSE}_{10}$, respectively. A parallel approach 
A) Lower-tail non-linearity in $\delta^{18} \mathrm{O}_{\text {coral }}$ - SST relationship ( $\mathrm{RMSE}_{10}$ )

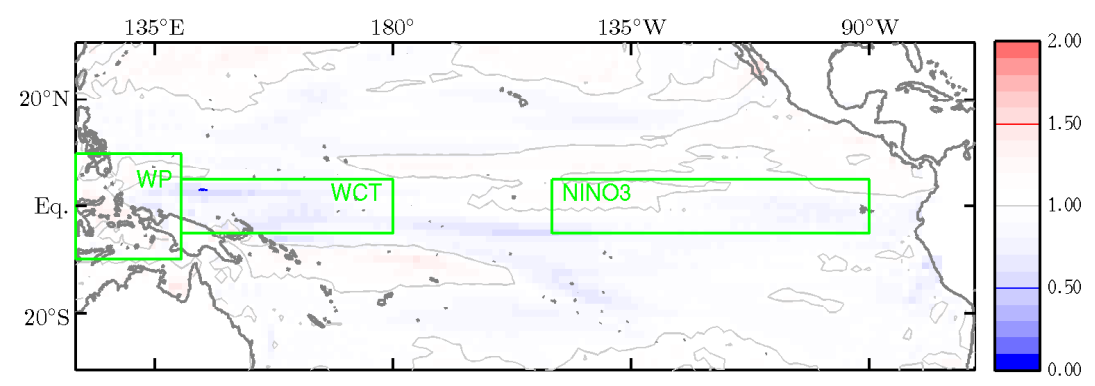

B) Upper-tail non-linearity in $\delta^{18} \mathrm{O}_{\text {coral }}$ - SST relationship ( $\mathrm{RMSE}_{90}$ )

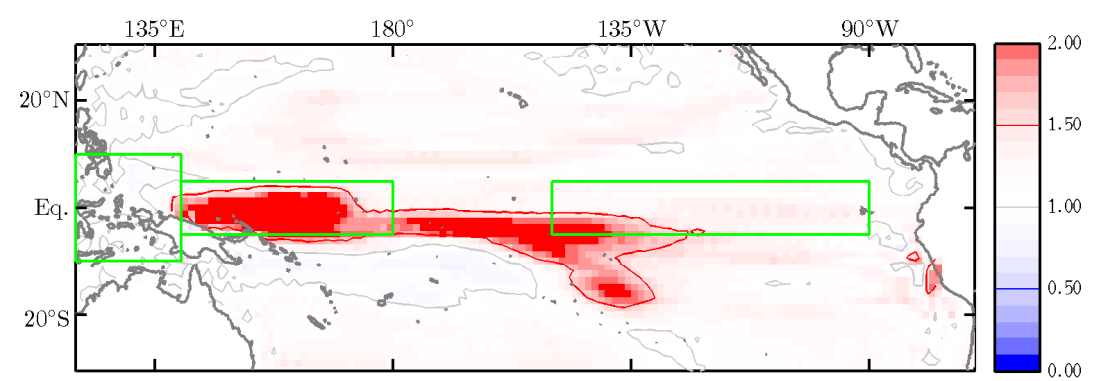

Fig. 4. The spatial distributions over the tropical Pacific domain of (A) the RMSE 10 non-linearity metric, which shows the extent of nonlinearity in the model $\delta^{18} \mathrm{O}_{\text {coral }}-\mathrm{SST}$ relationship for the eastern Pacific La Niña tail of ENSO events and (B) The RMSE 90 non-linearity metric, which shows the extent of non-linearity in the model $\delta^{18} \mathrm{O}_{\text {coral }}-\mathrm{SST}$ relationship for the eastern Pacific El Niño tail of ENSO events. The three regional boxes discussed in the text are highlighted in green, $\mathrm{WP}=$ warm pool, WCT $=$ Western cold tongue.

could be pursued for the $\delta^{18} \mathrm{O}_{\text {coral }}-\delta^{18} \mathrm{O}_{\text {sw }}$ relationship, but this is not considered at present, as the model region that shows the most evident non-linearities, the WCT, would be much harder to interpret in terms of $\delta^{18} \mathrm{O}_{\mathrm{sw}}$ than SST (having an $F_{\mathrm{sw}}$ value of 0.25 ). The regional WCT box shows a value of $\mathrm{RMSE}_{90}$ value of 2.0, indicating a standard error associated with the El Niño tail twice as great as the combined data, whereas the associated $\mathrm{RMSE}_{10}$ value and that of both metrics for NINO3 and the warm pool boxes remain within $\sim 0.2$ of unity (Fig. 3d-f). Considering the grid-box scale spatial distribution of these metrics, it is seen that the lower-tail metric remains close to unity everywhere (Fig. 4a), but the upper tail metric shows values exceeding 2 across much of the central and western equatorial Pacific (Fig. 4b). It is noted that the first-order pattern of the regions manifesting high $\mathrm{RMSE}_{90}$ values is similarly restricted to the central Pacific as that for which the inter-annual variability in precipitation is very high relative to the associated mean value (Fig. 1f). Using this observation and the regional average over the WCT box as an example, we can now seek to understand the origins of these effects.

The relationship between inter-annual SST and precipitation anomalies within the WCT box is non-linear, with large El Niño events associated with precipitation an order of magnitude greater than the mean value (Fig. 5a). In the case of the ENSO system, such non-linearity may arise from both thermodynamically and dynamically induced changes in precipitation. Furthermore, the isotopic composition of precipitation $\left(\delta^{18} \mathrm{O}_{\text {precip }}\right)$ over the open tropical ocean in the HadCM3 isotope regime is typically dominated by the precipitation amount effect (Tindall et al., 2009), such that high precipitation conditions also tend to be associated with relatively isotopically light precipitation, again in a non-linear fashion (Fig. 5b). The combination of these two non-linear relationships is that the net delivery of $\mathrm{O}^{18}$ to the surface ocean becomes more negative in a strongly non-linear fashion with the underlying SST anomalies (Fig. 5c). For values of the net precipitation isotope anomaly (the product of the precipitation anomaly and $\delta^{18} \mathrm{O}_{\text {precip }}$ ) more negative than $-50\left(\% \circ \times \mathrm{mmday}^{-1}\right)$, the effect on the model surface ocean layer $\delta^{18} \mathrm{O}_{\mathrm{sw}}$ isotopic mass balance is sufficient to account for a $0.1 \%$ shift towards lighter $\delta^{18} \mathrm{O}_{\mathrm{sw}}$ values (Fig. 5d), sufficient in turn to be noticeable relative to the associated SST variability (Fig. 3b). Such relatively large precipitation events are seen to occur almost exclusively during large eastern Pacific El Niño events, but not during all such events (Fig. 5c, d). Any dynamical contribution to the non-linear form of the $\delta^{18} \mathrm{O}_{\mathrm{sw}}-\mathrm{SST}$ relationship will itself be spatially variable, such that the WCT box average case presented here should be considered as an example of these relationships only. However, based on the process arguments advanced here it would seem reasonable to expect some manifestation of such effects in any case where two criteria are fulfilled; firstly, that ENSO-related precipitation extremes are 

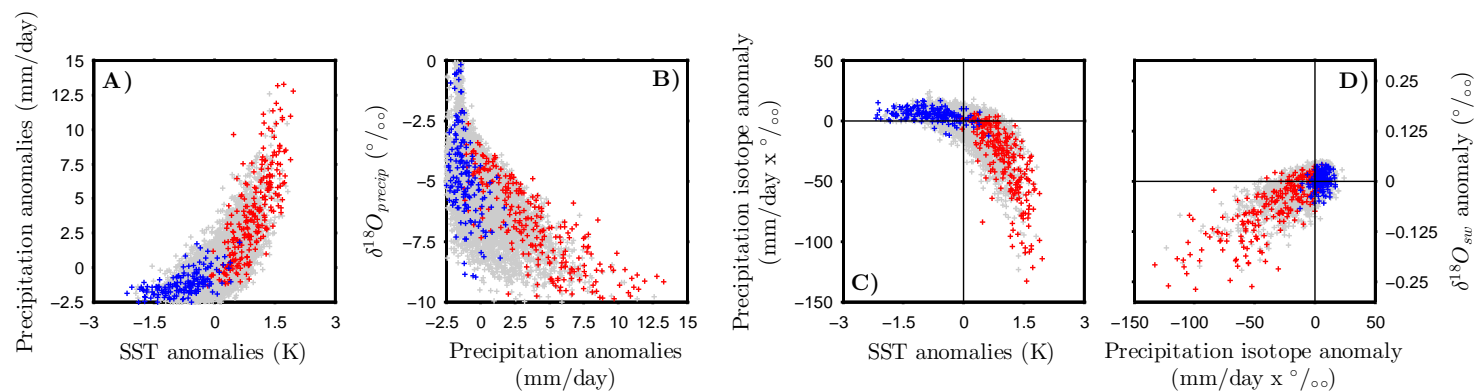

Fig. 5. Scatter plots of the relationships between (A) the inter-annual monthly anomalies of precipitation with SST, (B) the monthly interannual anomalies of precipitation and the isotopic composition of that precipitation $\left(\delta^{18} \mathrm{O}_{\text {precip }}\right)$, (C) the product of the precipitation anomalies and $\delta^{18} \mathrm{O}_{\text {precip }}$, referred to as the precipitation isotope anomaly, with SST and (D) the precipitation isotope anomaly and the $\delta^{18} \mathrm{O}_{\text {sw }}$ anomalies seen in the western cold tongue box (the location of which is shown on Figs. 2 and 4). The data points are color-coded according to the corresponding NINO3 SST anomalies, with the upper ten percentiles shown in red (eastern Pacific El Niño type conditions) and the lower ten percentiles in blue (eastern Pacific La Niña type conditions).

relatively large compared to the level of background precipitation variability and secondly, that the associated background variability in $\delta^{18} \mathrm{O}_{\mathrm{sw}}$ is relatively small, in the context of $\delta^{18} \mathrm{O}_{\text {coral }}$, compared to that in SST. If correct, then a form of correction for spatial model bias by spatial analogy may be possible. For example, the relationships seen within the model WCT box may be similar to those expected for the central Pacific NINO3.4 box $\left(5^{\circ} \mathrm{N}\right.$ to $5^{\circ} \mathrm{S}$ and $190^{\circ} \mathrm{E}$ to $240^{\circ} \mathrm{E}$ ). These criteria also allow us to understand why the warm pool and SPCZ regions do not also manifest a high RMSE90 value (Fig. 4b), in spite of containing large inter-annual precipitation variability and at least some non-linearity in their $\delta^{18} \mathrm{O}_{\mathrm{sw}}-\mathrm{SST}$ relationships (Fig. 3a). In these cases, the inter-annual $\delta^{18} \mathrm{O}_{\mathrm{sw}}$ variability is relatively large compared to that in SST (the warm pool box yields an $\left|F_{\mathrm{Sw}}\right|$ of 0.66$)$. Consequently, the overall $\delta^{18} \mathrm{O}_{\mathrm{sw}}-\mathrm{SST}$ relationship is relatively steep (for all ENSO phases) compared to that seen in the WCT (Fig. 3a, b), such that there is less scope for the manifestation of non-linearity in the associated $\delta^{18} \mathrm{O}_{\text {coral }}-\mathrm{SST}$ relationship. The strongest model nonlinearities are seen to occur in the region for which the cold tongue bias in terms of inter-annual SST amplitudes is the largest, namely the WCT. However, substantial El Niño tail non-linearity in the $\delta^{18} \mathrm{O}_{\text {coral }}-\mathrm{SST}$ relationship is also observed across much of the equatorial Pacific, including in regions for which the influence of the cold tongue bias is relatively modest (Fig. 4b). For example, the $\mathrm{RMSE}_{90}$ value for the averaged fields over the NINO4 box region, for which the inter-annual SST amplitude bias is much less pronounced in both absolute and relative terms than in the WCT, is 1.6. Whilst the case-study of the model WCT box may represent an upper bound to the extent of such behaviour that might be expected within the real climate system, the presence of such features is also unlikely to be a consequence of the underlying spatial biases in the HadCM3 ENSO realisation alone.
The non-linear relationships presented by the model SST and hydrological cycle variability have several potential implications for the interpretation of $\delta^{18} \mathrm{O}_{\text {coral }}$ records. Firstly and most generally, the asymmetric relationship between inter-annual precipitation anomalies and $\delta^{18} \mathrm{O}_{\text {precip }}$ (Fig. 5b) means that the noise added to the best-fit $\delta^{18} \mathrm{O}_{\text {coral }}-\mathrm{SST}$ relationship by $\delta^{18} \mathrm{O}_{\mathrm{sw}}$ will always be the greatest at the tail of the distribution associated with positive precipitation anomalies. Within the positive (negative) ENSO phase region, the uncertainties associated with reconstructing El Niño (La Niña) events in terms of SST will exceed those associated with La Niña (El Niño) events of equal magnitude. Secondly and perhaps most importantly, the interpretation of western and central equatorial Pacific model $\delta^{18} \mathrm{O}_{\text {coral }}$ in terms of an assumed linear relationship with SST may overestimate the magnitude of large SST anomalies in relation to moderate sized ones. In the case of grid-squares for which $\mathrm{RMSE}_{90}$ exceeds 2, including the regional average over the WCT box, the error in estimating the SST anomalies associated with the largest El Niño events approaches $20 \%$ of their true value. This remains the case even if a local calibration is available to constrain the best-fit linear $\delta^{18} \mathrm{O}_{\text {coral }}$-SST slope, although the model also suggests that the $R_{\mathrm{SST}-\text { coral }}$ slope could in fact also be used in all such regions with relatively little error. Furthermore, given that substantial non-linearities only occur in the western and central equatorial Pacific and not in the eastern equatorial Pacific (Fig. 4b), the estimation from coral records of the relative event amplitudes of "Central Pacific" and "Eastern Pacific" type El Niño events (Yeh et al., 2009) may be differentially affected by this uncertainty, in the sense of overestimating the relative size of Central Pacific events. Whether these non-linear effects will be detectable in real coral data is, however, contingent not only on the extent to which HadCM3 usefully represents the real system but also on the magnitude of any additional, nonclimatic noise present within real proxy records. 


\subsection{Assessing the stationarity of the relationships between $\delta^{18} \mathrm{O}_{\text {coral }}, \delta^{18} \mathrm{O}_{\text {sw }}$ and SST}

By dividing the $750 \mathrm{yr}$ model simulation into fifteen, nonoverlapping $50 \mathrm{yr}$ intervals and recalculating the $F_{\mathrm{sw}}, F_{\mathrm{cov}}$, $\mathrm{RMSE}_{10}$ and RMSE 90 metrics over these intervals, an assessment may be made of the multi-decadal stationarity of the relationships between $\delta^{18} \mathrm{O}_{\text {coral }}, \delta^{18} \mathrm{O}_{\mathrm{sw}}$ and SST within the temporal variability of the unforced model climate. The $50 \mathrm{yr}$ interval length is chosen to correspond roughly to the period for which a relatively high density of instrumental SST measurements are available for the tropical Pacific region (Rayner et al., 2003). Figure 6 shows the values of these four metrics averaged over the warm pool, WCT and NINO3 regions for both the whole control simulation (black dots) and $50 \mathrm{yr}$ intervals (grey dots). The inter-interval variability in the $F_{\mathrm{sw}}$ (Fig. 6a) and $F_{\mathrm{cov}}$ (Fig. 6b) metrics is less than 0.05 for the NINO3 box and less than 0.1 for the WCT and warm pool boxes. As this variability is sufficiently small, none of the conclusions derived in Sect. 3.1 would be altered were any given $50 \mathrm{yr}$ interval of model behaviour to have been used instead of the whole simulation. Therefore, if any forced contributions to 20th century changes in ENSO behaviour are neglected, the instrumental SST record should in principle be sufficient in duration to characterise the relative contributions from $\delta^{18} \mathrm{O}_{\mathrm{sw}}$ and SST to $\operatorname{var}\left(\delta^{18} \mathrm{O}_{\text {coral }}\right)$. This in turn suggests that, provided an equally long modern coral record is available for such locations, the $\delta^{18} \mathrm{O}_{\text {coral }}$ to SST calibration approach should allow for the robust representation of the first-order features of the true long-term relationship.

In the case of RMSE 10 (Fig. 6c) and RMSE90 (Fig. 6d), the $50 \mathrm{yr}$ interval values show more relative variability than was seen for the fraction of variance metrics, as the apparent extent of non-linearity present in the $\delta^{18} \mathrm{O}_{\mathrm{sw}}-\mathrm{SST}$ relationships is sensitive to the event magnitude distribution, which is harder to characterise over shorter periods. However, the $\mathrm{RMSE}_{10}$ and $\mathrm{RMSE}_{90}$ interval values are seen to remain within the range $0.5-1.5$ in all cases except for RMSE$_{90}$ within the WCT box (Fig. 6c, d). In this latter case, for which significant El Niño tail non-linearity in the $\delta^{18} \mathrm{O}_{\text {coral }}$-SST relationship is present in the whole record average, it is seen that this conclusion would now be dependent on the choice of $50 \mathrm{yr}$ interval. This situation arises because a given interval of this duration may happen to not contain any El Niño events of sufficient magnitude to manifest the non-linear precipitation-induced $\delta^{18} \mathrm{O}_{\mathrm{sw}}-\mathrm{SST}$ relationship discussed in Sect. 3.2. Therefore, if the instrumental record is not sufficiently long to capture the full extent of unforced ENSO event magnitudes (Wittenberg, 2009), it may then also fail to capture the second-order features, such as the non-linearities discussed here, of western and central equatorial Pacific $\delta^{18} \mathrm{O}_{\text {coral }}-\mathrm{SST}$ relationships. Equivalently, the intercomparison of modern and fossil (or fossil and fossil) coral records in terms of their western and central equatorial
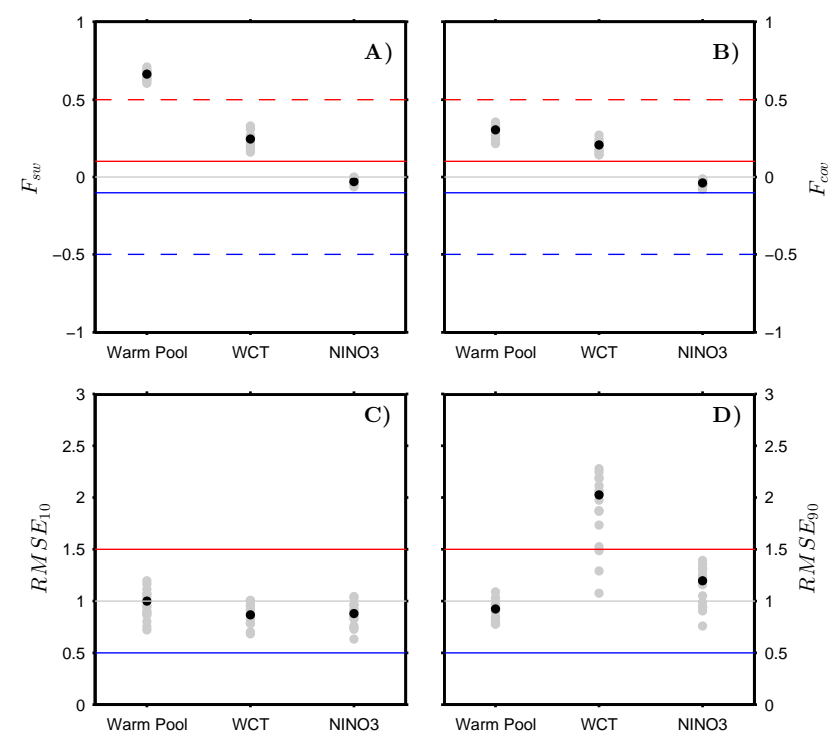

Fig. 6. Values of the (A) $F_{\mathrm{sw}}$, (B) $F_{\mathrm{cov}},(\mathbf{C}) \mathrm{RMSE}_{10}$ and (D) RMSE $_{90}$ metrics calculated over the warm pool, western cold tongue (WCT) and NINO3 boxes using both the entire $750 \mathrm{yr}$ of model simulation data (black dots) and also this same data split into fifteen non-overlapping $50 \mathrm{yr}$ intervals (grey dots). The locations of these regions are shown on Figs. 2 and 4. The solid and dashed reference lines represent the contoured levels shown on Fig. 2 (for $F_{\mathrm{SW}}$ and $F_{\text {cov }}$ ) and Fig. 4 (for RMSE 10 and RMSE90).

Pacific El Niño-related SST event magnitude distributions is likely to only be robust when continuous records of longer than $50 \mathrm{yr}$ duration are available.

\subsection{Comparing HadCM3 $\delta^{18} \mathrm{O}_{\text {coral }}$ and salinity-based $\delta^{18} O_{\text {pseudo-coral }}$}

Let us now imagine that the HadCM3 control simulation did not in fact directly resolve $\delta^{18} \mathrm{O}_{\mathrm{sw}}$ within the model climate. In such a case, a model pseudo-coral based on a plausible substitute hydrological cycle variable, such as SSS, could perhaps have been used in a forward model for the unknown $\delta^{18} \mathrm{O}_{\mathrm{sw}}$ fluctuations (Thompson et al., 2011). One advantage of such an approach, relative to making the simpler assumptions regarding $\delta^{18} \mathrm{O}_{\mathrm{sw}}$ outlined above, is that the relationship between SSS and $\delta^{18} \mathrm{O}_{\mathrm{sw}}$ might reasonably be expected to be more linear than that between SST and $\delta^{18} \mathrm{O}_{\text {sw }}$ (Cole and Fairbanks, 1990; Fairbanks et al., 1997). Initial support for such an assertion within the HadCM3 climate comes from the first-order similarity in the spatial patterns of inter-annual variance in SSS and $\delta^{18} \mathrm{O}_{\text {sw }}$ (Fig. 1c, d, g, h). However, the validity of such an approach also requires that the additional processes occurring within the isotope-enabled HadCM3 atmosphere model that also affect $\delta^{18} \mathrm{O}_{\mathrm{sw}}$, such as those that affect $\delta^{18} \mathrm{O}_{\text {precip }}$, are unimportant in relation to those occurring within the oceanic conservative tracer regime. To investigate this assumption, the regional scale relationships between 

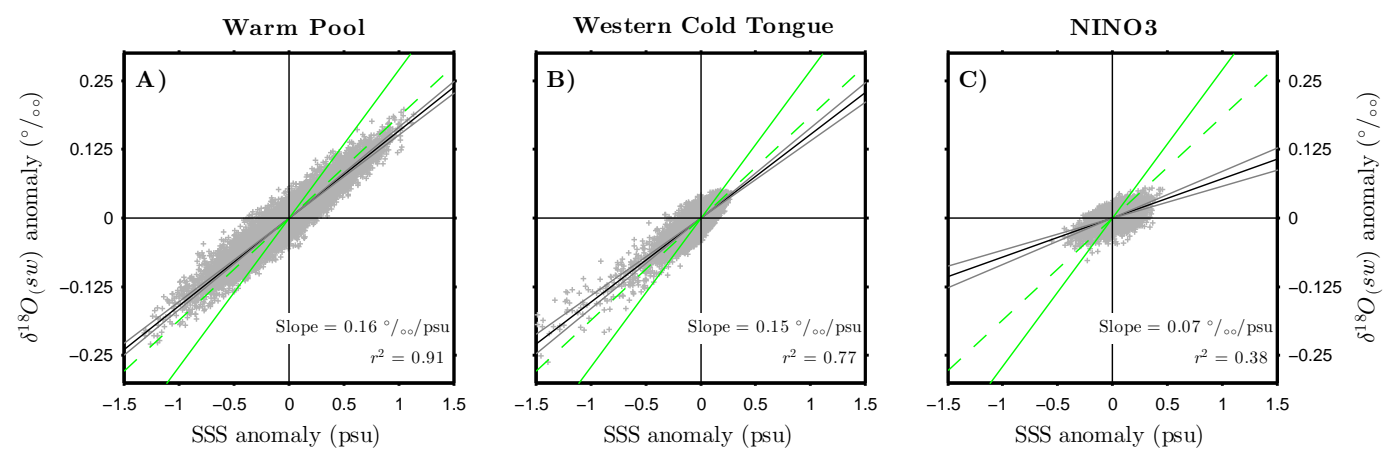

Fig. 7. Scatter plots of the relationships between the inter-annual monthly anomalies of $\delta^{18} \mathrm{O}_{\mathrm{sw}}$ and SSS as calculated for the spatial averaged indices over the warm pool, western cold tongue and NINO3 boxes. The locations of these regional boxes are shown on Figs. 2 and 4 . The black regression lines show the best-fit linear regressions through the data, with the slope and $r^{2}$ values annotated on the plots. The grey lines show the two-tailed $95 \%$ confidence bounds on the best-fit regression slopes, based on the assumption of an assumed decorrelation time of $4 \mathrm{yr}$. The solid green lines show the slope of $0.27 \% \mathrm{psu}^{-1}$ derived from a spatial regression of available instrumental data (LeGrande and Schmidt, 2006). The dashed green lines show the slope of $0.19 \% \circ \mathrm{psu}^{-1}$ derived from a spatial regression (across all grid-squares in the tropical Pacific domain) of the temporal means of the model data.

inter-annual SSS and $\delta^{18} \mathrm{O}_{\mathrm{sw}}$ variability are presented for the warm pool, WCT and NINO3 boxes and all three are seen to be well represented by a positive linear model (black lines on Fig. 7). This supports the principle of the pseudo-coral approach and even suggests that it should be able to capture the non-linear behaviour seen in the WCT $\delta^{18} \mathrm{O}_{\mathrm{sw}}$-SST relationship. However, the slopes and associated $r^{2}$ values range from $0.16 \% \mathrm{psu}^{-1}\left(r^{2}=0.91\right)$ for the warm pool box to $0.07 \% \mathrm{psu}^{-1}\left(r^{2}=0.38\right)$ for the NINO3 box. It follows that the unforced HadCM3 climate contains considerable spatial variability in the temporal slope of its inter-annual $\delta^{18} \mathrm{O}_{\mathrm{sw}^{-}}$ SSS relationships, which may be hard to capture through the use of any single value, such as what might be derived from a spatial regression. In particular, all three regional temporal slope values are lower than the value of $0.27 \% \circ \mathrm{psu}^{-1}$ (shown as the solid green line on Fig. 7) derived from the spatial relationship seen between the available SSS and $\delta^{18} \mathrm{O}_{\mathrm{sw}}$ data (Fairbanks et al., 1997; LeGrande and Schmidt, 2006). This discrepancy is not due to the exclusion of intra-annual variability from the model regressions, as the same calculations performed on the monthly mean data yield very similar values. It may, however, be attributable to either model bias and/or the incomplete spatio-temporal sampling offered by the available instrumental data.

To further investigate the stability of the temporal and spatial $\delta^{18} \mathrm{O}_{\mathrm{sw}}$-SSS relationships, the same analysis undertaken on the $F_{\mathrm{sw}}, F_{\mathrm{cov}}, \mathrm{RMSE}_{10}$ and RMSE 90 metrics in Fig. 6 was also replicated for the $\delta^{18} \mathrm{O}_{\mathrm{sw}}-\mathrm{SSS}$ regression slopes. In the case of the WP, WCT and NINO3 regional temporal slopes, the range of the values calculated within the nonoverlapping $50 \mathrm{yr}$ chunks is sufficient to overlap with those calculated for the temporal slopes of the data averaged across the entirety of the tropical Pacific (Fig. 8). However, all of these ranges remain distinct from the spatial slope of the HadCM3 $\delta^{18} \mathrm{O}_{\mathrm{sw}}-\mathrm{SSS}$ relationship, as calculated using the

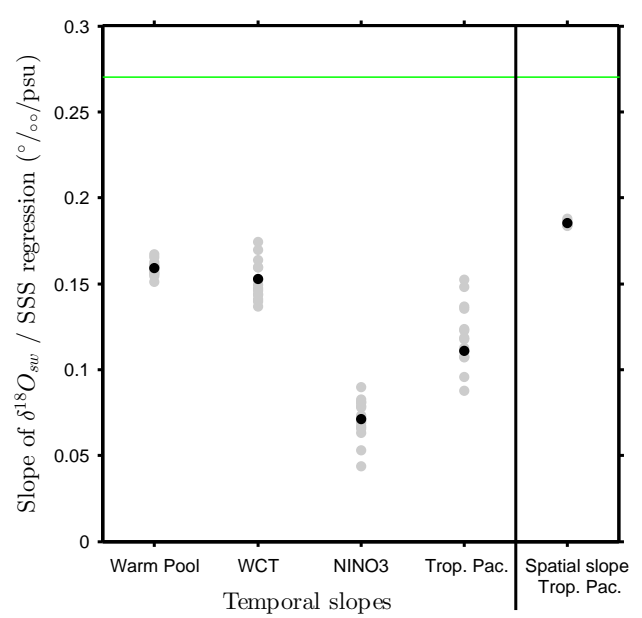

Fig. 8. Values of the $\delta^{18} \mathrm{O}_{\mathrm{sw}}-\mathrm{SSS}$ temporal regression slopes calculated using the spatial averages over the warm pool, western cold tongue (WCT) and NINO3 boxes, as well as the entirety of the tropical Pacific domain (defined as $30^{\circ} \mathrm{S}$ to $30^{\circ} \mathrm{N}$ and $120^{\circ} \mathrm{E}$ to $70^{\circ} \mathrm{W}$ ), using both the entire $750 \mathrm{yr}$ of model simulation data (black dots) and also this same data split into fifteen non-overlapping $50 \mathrm{yr}$ intervals (grey dots). Also shown is the spatial regression slope calculated using the means (calculated over either the entire simulation or the $50 \mathrm{yr}$ chunks) of the two variables over all the model grid squares within the tropical Pacific domain. The locations of the box regions are shown on Figs. 2 and 4. The green reference line shows the $0.27 \% \mathrm{psu}^{-1}$ value for the spatial tropical Pacific slope derived from instrumental data in LeGrande and Schmidt (2006).

mean values for these variables at each grid box within the tropical Pacific domain, with the latter term being very stable around a value of $0.19 \% \mathrm{psu}^{-1}$ (shown as the dashed green lines on Fig. 7) across the 50 yr intervals (Fig. 8). Furthermore, the inter-chunk ranges of all the model temporal and spatial slope values also remain considerably lower 
than the spatial regression of the available instrumental data (LeGrande and Schmidt, 2006) (shown as the solid green line on Fig. 8). Therefore, the discrepancy between the instrumental and HadCM3 spatial slopes cannot be attributed to such temporal sampling uncertainty and must arise from sampling uncertainty in the former and/or model bias issues. More importantly, whilst the regional differences in temporal slope seen across the entire model simulation might have been interpreted somewhat differently within any given $50 \mathrm{yr}$ interval, the observation that many of these values differ from that of the tropical Pacific spatial slope, regardless of whether this is inferred from the instrumental or model data, is likely to remain robust to such sampling. The observed variability in the temporal regression slopes between the different $50 \mathrm{yr}$ intervals may have arisen through sampling uncertainty within the noise associated with these relationships and/or non-stationary changes in the $\delta^{18} \mathrm{O}_{\mathrm{sw}}$-SSS relationships through time. The range of the temporal regression slopes amongst the non-overlapping $50 \mathrm{yr}$ chunks does not significantly exceed what would be expected through sampling uncertainty around the whole record values within a stationary climate, provided that the assumed decorrelation time of the tropical climate system exceeds 9 months (the two-tailed $95 \%$ confidence bounds for the regression slopes are shown for the example decorrelation time of $4 \mathrm{yr}$ as the grey lines on Fig. 7). This result does not mean that the temporal relationships are necessarily stationary on this (or indeed any other) timescale, simply that the range of slopes seen for the $50 \mathrm{yr}$ timescale are not inconsistent with the sampling uncertainty associated with regression noise within a stationary system. Such an outcome suggests that unforced multi-decadal changes in processes that affect $\delta^{18} \mathrm{O}_{\mathrm{sw}}$, but not SSS, such as changes in precipitation moisture source regions, are likely to be relatively unimportant compared to those processes which affect both variables (such as the regional precipitation-evaporation balance). This provides further support, in the context of the model climate, for the underlying principle of the salinity pseudo-coral approach. However, it also follows that the relatively noisy nature of many of the regional scale temporal $\delta^{18} \mathrm{O}_{\mathrm{sw}}-\mathrm{SSS}$ regressions means that records of multi-centennial duration are likely to be necessary to robustly establish these slopes.

Regardless of whether the instrumental or HadCM3 derived spatial $\delta^{18} \mathrm{O}_{\mathrm{sw}}$-SSS slope is used, the application of such a value will result in the overestimation of the temporal HadCM $3 \delta^{18} \mathrm{O}_{\text {sw }}-\mathrm{SSS}$ slope for all three example regions considered here (Fig. 7) and also at almost all grid-squares within the tropical Pacific (not shown). Consequently, the use of spatial $\delta^{18} \mathrm{O}_{\mathrm{sw}}$-SSS slopes within the pseudo-coral approach will lead to overestimation of the relative contribution from $\delta^{18} \mathrm{O}_{\mathrm{sw}}$ to $\operatorname{var}\left(\delta^{18} \mathrm{O}_{\text {pseudo-coral }}\right)$, when compared to either pseudo-corals modelled from the HadCM3 temporal $\delta^{18} \mathrm{O}_{\mathrm{sw}}-$ SSS slopes or those derived from the $\delta^{18} \mathrm{O}_{\mathrm{sw}}$ field itself. For example, if the instrumental spatial slope estimate of $0.27 \% \mathrm{psu}^{-1}$ were to be imposed, then the pseudo-coral would yield apparent $F_{\mathrm{sw}}$ values that are 0.10 to 0.15 higher than the true (in the sense of the isotope-enabled model) value in the case of the WCT and warm pool box averages. In these cases, this bias represents less than $40 \%$ of the true value in the isotope-enabled model, such that the pseudocoral represents a considerable absolute improvement on the approach of assuming constant $\delta^{18} \mathrm{O}_{\mathrm{sw}}$. However, such an approach also leaves considerable residual error and this is likely to be in the sense of overestimating the hydrological cycle contribution, rather than the underestimation inherent in the assumed constant value approach. In the case of the NINO3 region, for which the true isotope-enabled model $F_{\mathrm{sw}}$ values are very small, the pseudo-coral approach leads to an apparent $F_{\mathrm{sw}}$ value of 0.09 which, although small in absolute terms, represents a larger proportionate error in estimating the true value within the isotope-enabled model of this term than would have occurred had constant $\delta^{18} \mathrm{O}_{\text {sw }}$ been assumed instead.

In summary, whilst intra-model comparisons for the isotope enabled HadCM3 suggest that the salinity pseudocoral approach is well founded in principle, at least within the model climate, establishing the local (or even regional) slopes of the temporal $\delta^{18} \mathrm{O}_{\mathrm{sw}}$-SSS relationship remains a substantial limiting uncertainty in the application of such a method to non-isotope-enabled GCMs. The HadCM3 results are also consistent with those from other isotope enabled GCMs (LeGrande and Schmidt, 2009) in suggesting that the temporal slopes of such relationships cannot be readily estimated using associated spatial slopes, even were the latter to be well known.

\subsection{Directions for future work}

The structural uncertainty present in the assumption that the HadCM3 realisation of the ENSO phenomenon usefully represents that of the real climate system constitutes an inherent limitation in applying the results of the present study to the interpretation of real $\delta^{18} \mathrm{O}_{\text {coral }}$ records. Given the likely extent of spatial bias present within the HadCM3 realisation of predicted ENSO-related $\delta^{18} \mathrm{O}_{\text {coral }}$ variability, it would not be recommended to use the associated interannual $\delta^{18} \mathrm{O}_{\text {coral }}$-SST relationships (e.g. Fig. $3 \mathrm{~d}-\mathrm{f}$ ) as surrogates for real coral calibrations. However, the model analysis may still usefully suggest in which regions the absence of such calibrations may lead to relatively small, as opposed to first-order, errors in subsequent SST inferences. For example, the differing contributions from $\delta^{18} \mathrm{O}_{\text {sw }}$ to $\delta^{18} \mathrm{O}_{\text {coral }}$ could potentially account for some of the observed spatial variability in the slopes of empirical $\delta^{18} \mathrm{O}_{\text {coral }}-\mathrm{SST}$ calibration relationships (Evans et al., 2000). On a qualitative level, the present analysis suggests that combining, at least within any simple linear framework, $\delta^{18} \mathrm{O}_{\text {coral }}$ records from different regions of the tropical Pacific, in order to reconstruct a particular SST anomaly index may be challenging. Future work could seek to apply more sophisticated field 
reconstruction techniques (for example, Emile-Geay et al., 2013) to the isotope-enabled model output. Comparison of such analyses with those undertaken on SST-only and SSSderived coral pseudo-proxies would then allow for investigation of whether the inclusion of the isotope processes alters the extent to which the available spatial distribution of real $\delta^{18} \mathrm{O}_{\text {coral }}$ records affects the capacity of such techniques to reconstruct remote SST indices. From a modelling perspective, in order to better quantify the impact of the spatial biases on the results of the analysis presented here, future experiments could be undertaken with flux-corrected versions of isotope-enabled CGCMs such as HadCM3. However, whilst such an approach would act to correct climatological biases in SST, it would not necessarily account for other limitations within the model realisation of an ENSOlike phenomenon. A preferable strategy would be the intercomparison of a range of isotope-enabled CGCMs, including those with widely differing spatio-temporal manifestations of an ENSO-like phenomenon, an exercise that will only be possible as more such models become available.

\section{Conclusions}

Isotope-enabled CGCMs provide an alternative realisation of the tropical climate in which to explore the possible uncertainties associated with interpreting $\delta^{18} \mathrm{O}_{\text {coral }}$ records of past ENSO variability in the context of simple assumptions regarding the $\delta^{18} \mathrm{O}_{\text {sw }}$ contribution to this proxy system. Analysis of unforced climate variability within the isotope-enabled HadCM3 CGCM shows that the extent to which $\delta^{18} \mathrm{O}_{\text {sw }}$ is important to inter-annual $\delta^{18} \mathrm{O}_{\text {coral variability is strongly spa- }}$ tially dependent. In the eastern equatorial Pacific this contribution is very small, such that model corals from this region could be robustly interpreted in terms of SST variability alone. In contrast, the western equatorial Pacific $\delta^{18} \mathrm{O}_{\mathrm{sw}}$ variability accounts for $10-50 \%$ of coral variance, a component of which is correlated to the inter-annual SST variability, meaning that local calibrations of the local $\delta^{18} \mathrm{O}_{\text {coral }}{ }^{-}$ SST relationships are likely to be essential. The model also suggests that the relationship between central and western equatorial Pacific $\delta^{18} \mathrm{O}_{\mathrm{sw}}$ and SST becomes non-linear during large El Niño events. This non-linearity occurs due to relatively large ENSO-related precipitation events and implies difficulty in reconstructing the relative magnitudes of SST anomalies associated with El Niño events in the central Pacific. Furthermore, evaluation of the stationarity of the model relationships suggests that more than $50 \mathrm{yr}$ of data is required in order to constrain the extent of such non-linearities. Intramodel evaluation of a model salinity-based pseudo-coral approach shows that such a method captures the first-order features of the model $\delta^{18} \mathrm{O}_{\mathrm{sw}}$ relationships, although considerable residual uncertainty remains due to the difficulty of estimating the regional slopes of the temporal $\delta^{18} \mathrm{O}_{\mathrm{sw}}$-salinity relationships.
Acknowledgements. This work was funded through NERC grant NE/H009957/1.

Edited by: N. Abram

\section{References}

Cobb, K. M., Charles, C. D., Cheng, H., and Edwards, R. L.: El Niño/Southern Oscillation and tropical Pacific climate during the last millennium, Nature, 424, 271-276, doi:10.1038/nature01779, 2003.

Cole, J. E. and Fairbanks, R. G.: The Southern Oscillation recorded in the $\delta^{18} \mathrm{O}$ of corals from Tarawa Atoll, Paleoceanography, 5, 669-683, 1990.

Collins, M., Tett, S. F. B., and Cooper, C.: The internal climate variability of HadCM3, a version of the Hadley Centre coupled model without flux adjustments, Clim. Dynam., 17, 61-81, 2001.

Corrège, T.: Sea surface temperature and salinity reconstruction from coral geochemical tracers, Palaeogeogr. Palaeocl., 232, 408-428, 2006.

Cox, P. M., Betts, R. A., Bunton, C. B., Essery, R. L. H., Rowntree, P. R., and Smith, J.: The impact of new land surface physics on the GCM simulation of climate and climate sensitivity, Clim. Dynam., 15, 183-203, doi:10.1007/s003820050276, 1999.

Dunbar, R. B., Wellington, G. M., Colgan, M. W., and Glynn, P. W.: Eastern Pacific Sea Surface Temperature Since 1600 A.D.: The $\delta^{18} \mathrm{O}$ Record of Climate Variability in Galápagos Corals, Paleoceanography, 9, 291-315, doi:10.1029/93PA03501, 1994.

Emile-Geay, J., Cobb, K. M., Mann, M. E., and Wittenberg, A. T.: Estimating Central Equatorial Pacific SST Variability over the Past Millennium. Part I: Methodology and Validation, J. Climate, 26, 2302-2328, doi:10.1175/JCLI-D-11-00510.1, 2013.

Epstein, S., Buchsbaum, J. R., Lowenstam, H. A., and Urey, H. C.: Revised carbonate-water isotopic temperature scale, Bull. Geol. Soc. Am., 64, 1315-1326, 1953.

Evans, M. N., Kaplan, A., and Cane, M. A.: Intercomparison of coral oxygen isotope data and historical sea surface temperature (SST): Potential for coral-based SST field reconstructions, Paleoceanography, 15, 551-563, 2000.

Fairbanks, R. G., Evans, M. N., Rubenstone, J. L., Mortlock, R. A., Broad, K., Moore, M. D., and Charles, C. D.: Evaluating climate indices and their geochemical proxies measured in corals, Coral Reefs, 16, S93-S100, 1997.

Gagan, M. K., Ayliffe, L. K., Beck, J. W., Cole, J. E., Druffel, E. R. M., Dunbar, R. B., and Schrag, D. P.: New views of tropical paleoclimates from corals, Quaternary Sci. Rev., 19, 45-64, 2000.

Gordon, C., Cooper, C., Senior, C. A., Banks, H., Gregory, J. M., Johns, T. C., Mitchell, J. F. B., and Wood, R. A.: The simulation of SST, sea ice extents and ocean heat transports in a version of the Hadley Centre coupled model without flux adjustments, Clim. Dynam., 16, 147-168, doi:10.1007/s003820050010, 2000.

Guilyardi, E.: El Niño- mean state - seasonal cycle interactions in a multi-model ensemble, Clim. Dynam., 26, 329-348, 2006.

Juillet-Leclerc, A. and Schmidt, G.: A calibration of the oxygen isotope paleothermometer of coral aragonite from Porites, Geophys. Res. Lett, 28, 4135-4138, doi:10.1029/2000GL012538, 2001.

LeGrande, A. N. and Schmidt, G.: Global gridded data set of the oxygen isotopic composition in seawater, Geophys. Res. Lett., 
33, L12604, doi:10.1029/2006GL026011, 2006.

LeGrande, A. N. and Schmidt, G. A.: Sources of Holocene variability of oxygen isotopes in paleoclimate archives, Clim. Past, 5, 441-455, doi:10.5194/cp-5-441-2009, 2009.

Linsley, B. K., Wellington, G. M., and Schrag, D. P.: Decadal Sea Surface Temperature Variability in the Sub-tropical South Pacific from 1726 to 1997 A.D, Science, 290, 1145-1148, 2000.

Linsley, B. K., Wellington, G. M., Schrag, D. P., Ren, L., Salinger, M. J., and Tudhope, A. W.: Geochemical evidence from corals for changes in the amplitude and spatial pattern of South Pacific interdecadal climate variability over the last 300 years, Clim. Dynam., 22, 1-11, 2004.

Lough, J. M.: A strategy to improve the contribution of coral data to high-resolution paleoclimatology, Palaeogeogr. Palaeocl., 204, 115-143, 2004.

McConnaughey, T.: ${ }^{13} \mathrm{C}$ and ${ }^{18} \mathrm{O}$ isotopic disequilibrium in biological carbonates: I. Patterns, Geochim. Cosmochim. Ac., 53, 151162, 1989a.

McConnaughey, T.: ${ }^{13} \mathrm{C}$ and ${ }^{18} \mathrm{O}$ isotopic disequilibrium in biological carbonates: II. In vitro simulation of kinetic isotope effects, Geochim. Cosmochim. Ac., 53, 163-171, 1989b.

McGregor, H. V. and Gagan, M. K.: Western Pacific coral $\delta^{18} \mathrm{O}$ records of anomalous Holocene variability in the El Niño-Southern Oscillation, Geophys. Res. Lett, 31, L11204, doi:10.1029/2004GL019972, 2004.

McPhaden, M. J., Lee, T., and McClurg, D.: El Niño and its relationship to changing background conditions in the tropical Pacific Ocean, Geophys. Res. Lett., 38, L15709, doi:10.1029/2011GL048275, 2011.

Rayner, N. A., Parker, D. E., Horton, E. B., Folland, C. K., Alexander, L. V., Rowell, D. P., Kent, E. C., and Kaplan, A.: Global analyses of sea surface temperature, sea ice, and night marine air temperature since the late nineteenth century, J. Geophys. Res., 108, 4407, doi:10.1029/2002JD002670, 2003.

Schmidt, G. A., Bigg, G. R., and Rohling, E. J.: Global Seawater Oxygen-18 Database, available at: http://data.giss.nasa.gov/ o18data (last access: 1 October 2012), 1999.
Thompson, D. M., Ault, T. R., Evans, M. N., Cole, J. E., and EmileGeay, J.: Comparison of observed and simulated tropical climate trends using a forward model of coral $\delta^{18} \mathrm{O}$, Geophys. Res. Lett., 38, L14706, doi:10.1029/2011GL048224, 2011.

Tindall, J. C., Valdes, P. J., and Sime, L. C.: Stable water isotopes in HadCM3: Isotopic signature of El Niño-Southern Oscillation and the tropical amount effect, J. Geophys. Res., 114, D04111, doi:10.1029/2008JD010825, 2009.

Toniazzo, T.: Properties of El Niño - Southern Oscillation in Different Equilibrium Climates with HadCM3, J. Climate, 19, 4854 4876, doi:10.1175/JCLI3853.1, 2006.

Tudhope, A. W., Chilcott, C. P., McCulloch, M. T., Cook, E. R., Chappell, J., Ellam, R. M., Lea, D. W., Lough, J. M., and Shimmield, G. B.: Variability in the El Niño-Southern Oscillation Through a Glacial-Interglacial Cycle, Science, 291, 1511-1517, 2001.

Watanabe, T., Suzuki, A., Minobe, S., Kawashima, T., Kameo, K., Minoshima, K., Aguilar, Y. M., Wani, R., Kawahata, H., Sowa, K., Nagai, T., and Kase, T.: Permanent El Niño during the Pliocene warm period not supported by coral evidence, Nature, 471, 209-211, doi:10.1038/nature09777, 2011.

Wittenberg, A. T.: Are historical records sufficient to constrain ENSO simulations?, Geophys. Res. Lett., 36, L12702, doi:10.1029/2009GL038710, 2009.

Yeh, S.-W., Kug, J.-S., Dewitte, B., Kwon, M.-H., Kirtman, B. P., and Jin, F.-F.: El Niño in a changing climate, Nature, 461, 511514, doi:10.1038/nature08316, 2009.

Zhou, G.-T. and Zheng, Y.-F.: An experimental study of oxygen isotope fractionation between inorganically precipitated aragonite and water at low temperatures, Geochim. Cosmochim. Ac., 67, 387-399, 2003. 